\title{
ANÁliSE DE POLÍTICAS EDUCACIONAIS: A ABORDAGEM DO CICLO DE POLÍTICAS E AS CONTRIBUIÇÓES de Pierre Bourdieu
}

\author{
ANALYSES OF EDUCATIONAL POLICIES: THE POLICY CYCLE \\ APPROACH AND THE CONTRIBUTIONS OF PierRe Bourdieu
}

\begin{abstract}
Rayane Regina Scheidt Gasparelo Doutoranda em Educação - Universidade Estadual de Campinas (UNICAMP), São Paulo, SP - Brasil. Docente no Curso de Pedagogia da Universidade Estadual do Centro-Oeste (UNICENTRO), Irati, PR - Brasil rayanegasparelo.0706@gmail.com
\end{abstract}

Débora Cristina Jeffrey Professora Livre Docente: Universidade Estadual de Campinas (UNICAMP), Faculdade de Educaçâo, Coordenadora do Grupo de Estudos e Pesquisas em Política e Avaliação Educacional (GEPALE/UNICAMP). Vice-Presidente da Região Sudeste da Sociedade Brasileira de Educação Comparada (SBEC) debora.jeffrey@gmail.com

\begin{abstract}
Marisa Schneckenberg Professora Associada: Universidade Estadual do Centro-Oeste (UNICENTRO). Coordenadora do Grupo de Pesquisa Estado, Políticas e Gestão da Educação (GPEPGE/UNICENTRO)

marisaunicentro@hotmail.com
\end{abstract}

\begin{abstract}
Resumo: A investigação sobre políticas públicas, de sua formulação a sua implementação, requer considerar os determinantes históricos, econômicos, políticos, sociais e culturais que permeiam a sociedade. Nessa perspectiva, reconhece-se a dimensão do poder simbólico exercido pelos grupos de pressáo que definem os contornos que a política vai assumindo. Diante dessas teorizaçóes introdutórias, objetiva-se neste texto uma reflexão que articula os fundamentos da abordagem do Ciclo de Políticas proposta por Stephen Ball e Richard Bowe e as contribuiçóes conceituais de Pierre Bourdieu, para análise dos processos de formulação e implementação das políticas educacionais. Trata-se de um estudo de natureza teórica que evidencia o movimento dialético entre os contextos de influência, de produção de texto e de prática na instauração de uma política pública, e a pertinência dos conceitos de habitus, campo e poder simbólico para analisar a articulação entre tais contextos. Conclui-se que o processo de traduzir políticas em práticas constitui quase uma peça teatral, para a qual se propóe um roteiro, mas cuja realização ocorre quando os sujeitos a representam. Por esse viés, a abordagem do Ciclo de Políticas aponta para a investigação das políticas públicas em seus processos e desdobramentos macro e micro políticos, e os escritos de Pierre Bourdieu, por sua vez, podem contribuir para o desvelamento das açôes, discursos, necessidades (legais e institucionais), crenças e valores discordantes, inconsistentes e contraditórios, relaçóes de poder desiguais (de vários tipos), ausências e constrangimentos materiais e contextuais dos atores que estão envolvidos com as políticas nos níveis global e local.
\end{abstract}

Palavras-chave: Campo. Ciclo de Políticas. Habitus. Políticas Educacionais. Poder Simbólico. 
Abstract: Public policy research, from its formulation to its implementation, requires consideration of the historical, economic, political, social, and cultural determinants that permeate society. From this perspective, we recognize the dimension of the symbolic power exerted by the pressure groups that define the contours that politics is assuming. In the light of these introductory theories, this paper aims at a reflection that articulates the fundamentals of the policy cycle approach proposed by Stephen Ball and Richard Bowe and the conceptual contributions of Pierre Bourdieu, to analyze the processes of formulation and implementation of educational policies. Therefore, it is a study of a bibliographic nature, evidencing the dialectical movement between the context of influence, of text production and of practice in the and the pertinence of the concepts of habitus, field and symbolic power to analyze the articulation between such contexts. It is concluded that the process of translating politics into practices constitutes almost a play, for which a script is proposed, but whose realization occurs when the subjects represent it. By this bias, the approach of the Policy Cycle points to the investigation of public policies in its processes and macro and micro political developments, and through this bias, the writings of Pierre Bourdieu can contribute to the unveiling of actions, discourses, legal needs and institutional), discordant, inconsistent and contradictory beliefs and values, unequal power relations (of various kinds), absences, and material and contextual constraints of actors who are involved with policies at the global and local levels.

Keywords: Field. Policy Cycle. Habitus. Educational Policies. Symbolic Power.

\section{Introduçáo}

Bourdieu (2014) conceitua o campo político como o lugar por exce-

Os fazedores da política, ao tomarem decisões que conduzem à sua definição e formulação, estấo se apoiando em algum tipo de definição social da realidade, peculiar a determinados grupos que atuam no setor concernente. Tratam-se de formas de conhecimento e de interpretação do real próprias de alguns, que procuram manter ou conquistar a hegemonia de uma dada esfera de ação. (AZEVEDO, 1997, p. 65)

Nessa perspectiva, é oportuno registrar que as políticas “[...] podem se manifestar em qualquer nível e não apenas no âmbito do governo cen- 
tral." (VIEIRA, 2009, p. 23-24) No entanto, a mesma autora reconhece que a força do poder central, isto é, da União, tende a ensombrar o espaço do poder intermediário, os estados federados, e influenciar na relação destes com o poder local concentrado nos municípios e nas escolas: "É certo que sob as circunstâncias de uma sociedade em rede, o local termina por 'subordinar-se' ao global, ajustando-se inclusive, aos ditames de organizaçôes internacionais, como o Banco Mundial [...]” (VIEIRA, 2011, p. 129) Asprella (2013, p. 93) exemplifica essa questáo ao afirmar que:

$\mathrm{Na}$ década de noventa o conteúdo das políticas de educação centrava-se fortemente sobre as reformas educacionais conhecidas e difundidas, praticamente toda a América Latina, com forte influência de agências internacionais, estando ausente advertências sobre o verdadeiro destino dessas reformas e mudanças [...].

Nesse cenário prevaleceram (e ainda prevalecem) os interesses dos organismos multilaterais, suas influências e articulações. Esse exemplo corrobora o assinalado por Azevedo (1997), impondo a compreensão de que as políticas assumem determinados contornos conforme os interesses dos grupos de pressão. Assim, cada formulação política referente ao contexto social "[...] apresenta arenas, lugares e grupos de interesse e envolve disputas e embates." (MAINARDES; FERREIRA; TELLO, 2011, p. 157) Portanto, "[...] uma política pública é um constructo social." (op. cit., p. 161), e, assim,

O processo de formulação de políticas é considerado como um ciclo contínuo, no qual as políticas são formuladas e recriadas. Os três ciclos principais do ciclo de políticas são o contexto de influência, a produção de texto e o contexto da prática. Esses contextos são intimamente ligados e inter-relacionados, não têm dimensão temporal nem sequencial e não constituem etapas lineares. (op.cit., p. 157)

Cabe, então, explicitar que as políticas públicas sociais surgem na relação de forças entre os protagonistas da sociedade civil (escolas, igrejas, 
partidos políticos, sindicatos, organizaçóes profissionais, meios de comunicação) e da sociedade política (poderes executivo, judiciário, legislativo), e que é nesse diálogo que se definem as açóes governamentais. Seria equívoco conceber as políticas públicas como imposiçôes estatais e governamentais desconectadas do conjunto fatores econômicos, políticos, sociais e culturais, conforme expóe Gomes (2011, p. 19):

As políticas públicas são construçôes sociais e históricas cujos determinantes são necessariamente complexos e múltiplos. Tais determinantes podem ser classificados, em linhas gerais, como sociais, culturais, políticos e econômicos.

Dessa forma, ao investigar as políticas da educação precisamos compreendê-las para além de uma esfera determinada basicamente pela economia, pois "[...] nela determinações de inúmeras origens terminariam por se entrecortar e por anular a exclusividade causal de qualquer uma." (MAINARDES; FERREIRA; TELLO, 2011, p. 160)

Diante dessas teorizaçóes introdutórias, objetiva-se neste texto uma reflexão que articula os fundamentos da abordagem do Ciclo de Políticas proposto por Stephen Ball e Richard Bowe e as contribuiçôes conceituais de Pierre Bourdieu, para análise dos processos de formulação e implementação das políticas educacionais.

\section{Proposiçóes teórico-metodológicas de Ball, Bowe e Bourdieu: articulaçóes pertinentes}

As políticas públicas são materializadas nas açôes do Estado destinadas à implantação de um projeto de governo, com programas, projetos e planos voltados aos diferentes setores pelos quais se organizam as sociedades como transporte, saúde, bancário, agrícola, industrial, etc. Contudo, dado que o processo político é algo complexo e dialético,

As políticas públicas são aqui compreendidas como as de responsabilidade do Estado - quanto à implementação e manutenção a partir de um processo de tomada de decisóes que 
envolve órgãos públicos e diferentes organismos e agentes da sociedade relacionados à política implementada. (HÖFLING, 2001, p. 31)

Assim, os dirigentes/administradores/governantes têm autoridade e legitimidade para que, por meio de suas açôes, conduzam a coletividade. Em tais direcionamentos, dependendo da forma como esse poder é exercido, irão determinar o modelo de proteção social a ser implementado pelo organismo estatal, na medida em que "[...] este pode ser voltado à submissão dos participantes da coletividade, inserindo-se aí a tecnocracia, ou seja, o poder das elites, ou à participação da sociedade como um todo, voltada então à democracia." (MARTINS et al., 1999, p. 11)

Nessa discussão, Bourdieu (2014, p. 228) esclarece que "O efeito mais paradoxal do Estado é o da crença. O Estado é essa instituição que tem o poder extraordinário de produzir um mundo social ordenado sem necessariamente dar ordens, sem exercer coerção permanente.” A existência de uma ordem simbólica e, com ela, de uma ordem social, pode ser exemplificada com o fato de que as pessoas param no sinal vermelho sem que haja um guarda atrás de cada automobilista. Isso quer dizer que entre os sujeitos sociais há uma acumulação de capital simbólico que pode explicar essa espécie de obediência generalizada, sem apelar para a coerção. É assim que,

Ao inculcar - em grande parte pelo sistema escolar - estruturas cognitivas comuns, tacitamente avaliativas, ao produzilas, ao reproduzi-las, ao fazê-las reconhecer profundamente, ao fazê-las incorporar, o Estado dá uma contribuição essencial à reprodução da ordem simbólica, que colabora de maneira determinante para a ordem social e para sua reprodução. Impor estruturas cognitivas e avaliativas idênticas é fundar um consenso sobre o sentido do mundo. (op.cit., p. 230)

Nesses sentidos, o ponto de partida é a dimensão simbólica, ou seja, o poder simbólico/invisível que intervém nas relaçóes de força fundamentais da ordem social, pois "[...] se as relaçóes de força fossem apenas relaçôes de força física, militares ou econômicas, é provável que fossem infini- 
tamente mais frágeis e facílimas de inverter." (op. cit., p. 224) Diante desse quadro conceitual, Bourdieu (op. cit., p. 276) propóe:

[...] pensar o Estado como um instrumento de organizaçáo social capaz de fundamentar um conformismo lógico e um conformismo moral e, até mesmo, um consenso, mas em um sentido muito especial. Insisto no fato de que essa integração lógica e moral produzida pelo Estado é a condição mesma da dominação que o Estado é passível de exercer a serviço dos que podem se apropriar do Estado.

$\mathrm{Na}$ visão do autor, há um consentimento dos agentes quanto à autoridade do Estado, um capital simbólico de submissão generalizada a esse ente: "O Estado, parece-me, deve ser pensado como produtor de princípios de classificação, isto é, de estruturas estruturantes capazes de serem aplicadas a todas as coisas do mundo, em especial as coisas sociais." (op.cit., p. 227) Esse entendimento se evidencia quando o autor dispóe que o espaço social é construído conforme o capital econômico e cultural dos agentes ou grupos. No entanto, quando o capital cultural é maior que o capital econômico, os grupos ou agentes possuidores desse capital tendem a oporse aos detentores de um grande volume de capital global (econômico e cultural). Na sociedade, portanto,

[...] a influência dos diversos setores, e dos grupos que predominam em cada setor, vai depender do grau de organização e articulação destes grupos com ele envolvidos. Este é um elemento chave para que se compreenda o padrão que assume uma determinada política e, portanto, é escolhida uma determinada solução e não outra, para a questáo que estava sendo alvo de problematização. (AZEVEDO, 1997, p. 63)

Por isso, ao analisar as políticas educacionais, Mainardes (2006, p. 50) aponta [...] "um ciclo contínuo constituído por três contextos principais: o contexto de influência, o contexto da produção do texto e o contexto da prática." 


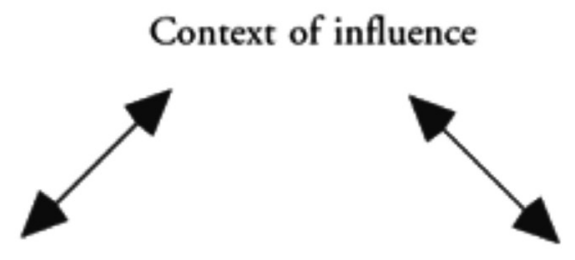

Context of policy text production
Context of

practice

\section{Figura 1: Ciclo de Políticas}

Fonte: Bowe et al (1992, p. 20 apud MAINARDES, 2006, p. 51).

Os contextos: de influência, de produção de texto e de prática não compóem uma estrutura hierárquica, ao contrário, dialogam e interagem, permitindo ao pesquisador compreender a variedade de determinantes no processo de formulação e implementação de uma política.

O contexto de influência, segundo Mainardes (2006), é aquele no qual as políticas públicas são originadas e os discursos políticos são arquitetados, no qual os grupos de interesse como partidos políticos, comissôes e grupos representativos influenciam, disputam e definem as finalidades sociais da educação, idealizam conceitos e elaboram um discurso de base para a política. Já o contexto da produção de texto ocorre de acordo com o contexto de influência, mas, "[...] ao passo que o contexto de influência está frequentemente relacionado com interesses mais estreitos e ideologias dogmáticas, os textos políticos normalmente estão articulados com a linguagem do interesse público mais geral.” (op.cit., p. 52)

Dessa forma, os textos políticos expressam o desfecho de disputas e acordos dos diferentes grupos que coordenam as representaçóes da política. Compóem esse contexto textos, comentários, pronunciamentos e vídeos legais, formais ou informais, que podem ser contraditórios, dúbios e enigmáticos. Mainardes e Gandin (2013, p. 154) explicitam que a análise do contexto da produção do texto implica:

[...] a leitura e compreensão crítica dos textos, por meio da identificação dos seus componentes políticos-ideológicos; 
as relaçôes de poder envolvidas na formulação de políticas; os sujeitos (autores e influenciadores), as instituiçóes e as redes de influência que estão envolvidos na formulação de políticas; as relaçôes dos textos de uma política específica com textos de políticas de outros contextos e com políticas setoriais etc.

Assim, cada texto político gera uma consequência na realidade. Essas consequências são vivenciadas no contexto da prática, contexto no qual as políticas ganham sentido. No caso das políticas educacionais, implica que os "[...] profissionais que atuam no contexto da prática (escolas, por exemplo) não enfrentam os textos políticos como leitores ingênuos, eles vêm com suas histórias, experiências, valores e propósitos." (BOWE et al., 1992 apud MAINARDES, 2006, p. 53)

Nessa perspectiva, o ciclo conduz para uma análise que contempla o espaço escolar e o espaço social como loci de criação e recriação das políticas oficiais, impondo ao pesquisador a verificação e compreensão das rearticulaçóes e embates que se processam em cada um dos contextos "[...] desde onde a política é gestada, passando pela produção do texto até a sua chegada ao local onde os agentes a vivenciam." (MAINARDES; GANDIN, 2013, p. 150)

Ao buscamos fundamentar as análises das políticas com os conceitos de habitus, campo e poder simbólico de Bourdieu (2003, 2004, 2011a, 2011b, 2011c) e Bourdieu e Passeron (2014) pode-se melhor compreender os mecanismos de conservação e reprodução que operam nas atividades humanas e nos diferentes espaços sociais, visto que somos agentes quando atuamos e escolhemos os princípios geradores e organizadores das nossas práticas, ações, representaçóes e pensamentos. Por esse viés, a perspectiva do Ciclo de Políticas, que aponta para a importância de analisar o discurso das políticas, é coerente com a identificação que Bourdieu (2004) faz de suas obras, caracterizando-as como 'estruturalista-construtivista'.

Se eu tivesse que caracterizar meu trabalho em duas palavras, ou seja, como se faz muito hoje em dia, se tivesse que lhe aplicar um rótulo, eu falaria de constructivist structuralism ou de structuralist constructivism [...] Por estruturalismo ou estruturalista, 
quero dizer que existem, no próprio mundo social e não apenas nos sistemas simbólicos - linguagem, mito etc. -, estruturas objetivas, independentes da consciência e da vontade dos agentes, as quais são capazes de orientar ou coagir suas práticas e representaçôes. Por construtivismo, quero dizer que há, de um lado, uma gênese social dos esquemas de percepção, pensamento e ação que são constitutivos do que chamo de habitus e, de outro, das estruturas sociais, em particular do que chamo de campos e grupos, e particularmente do que se costuma chamar de classes sociais. (BOURDIEU, 2004, p. 149)

Se o conceito de habitus representa a internalização de fatores resultantes das condiçôes históricas e sociais vividas ao longo da história pessoal e profissional dos agentes, então suas práticas sociais são construídas considerando a estrutura das posiçóes objetivas (regras estruturais dadas), a subjetividade dos sujeitos (princípios aprendidos pelo corpo e apreensão intelectual/conhecimento da realidade além do senso comum) e as situações concretas de ação. Com isso, Bourdieu (2011b) quer dizer que o habitus é adquirido na e pelas experiências práticas, formando um modelo de percepção, ação e apropriação que conduz o agente nas conjunturas do campo em que está inserido. Nesse sentido, o habitus, coerente com os princípios do arbitrário cultural que visa reproduzir (conservador ou revolucionário), produzido principalmente (mas não somente) pelo sistema de ensino, reflete nas açóes dos sujeitos. Portanto, se a ação (consciente ou inconsciente) dos agentes, seja pela inculcação ou pela exclusão, impuser às classes dominadas e dominantes o reconhecimento da cultura dominante, exercerá sua função de reprodução cultural.

Ao acompanharmos esse argumento compreendemos que os agentes sociais são socializados numa determinada ordem simbólica que os leva a cumprir os desideratos de uma determinada ordem social: "[...] O reconhecimento da legitimidade é um ato de conhecimento: [...] um ato de submissão dóxico à ordem social.” (BOURDIEU, 2014, p. 237) Nessa lógica, o poder exercido pelas palavras nas estruturas de um campo diferencia-se de acordo com a representação social, política, institucional e cultural que cada sujeito tem. Isso significa que: 
Todo poder de violência simbólica, isto é, todo poder que chega a impor significaçóes e a impô-las como legítimas, dissimulando as relaçôes de força que estão na base de suas forças, acrescenta sua própria força, isto é, propriamente simbólica, a essas relações de força. (BOURDIEU; PASSERON, 2014, p. 25)

É assim que, em outros escritos, Bourdieu (2011b, p. 14) esclarece que

O poder simbólico como poder de constituir o dado pela enunciação, de fazer ver e fazer crer, de confirmar ou de transformar a visão do mundo e, deste modo, a ação sobre o mundo, portanto o mundo; poder quase mágico que permite obter o equivalente daquilo que é obtido pela força (física ou econômica) graças ao efeito específico de mobilização.

Nesse sentido, há em cada campo aqueles que exercem mais poder através da comunicação que outros, validando algumas crenças em detrimento de outras, de modo que quem exerce o poder de direcionamento das relaçôes sociais pode alterar e/ou conservar certas visóes de mundo. De maneira mais pontual,

Isto significa que o poder simbólico [...] define numa relação determinada - e por meio desta - entre os que exercem o poder e os que lhe estão sujeitos, quer dizer [...] na própria estrutura do campo em que se produz e se reproduz a crença. O que faz o poder das palavras e das palavras de ordem, poder de manter a ordem ou de a subverter, é a crença na legitimidade das palavras e daquele que as pronuncia, crença cuja produção não é da competência das palavras. (op.cit., p. 14-15)

Por essa visão,

[...] que pode parecer abstrata e obscura, enuncia a primeira condição de uma leitura adequada da análise da relação entre as posiçôes sociais (conceito relacional), as disposiçôes (ou os habitus) e as tomadas de posiçôes, as "escolhas" que os agentes 
sociais fazem nos domínios mais diferentes da prática, na cozinha ou no esporte, na música ou na política etc. (BOURDIEU, 2011c, p. 18)

Com esse olhar, refletir sobre as políticas educacionais na sua especificidade significa considerar os diferentes espaços sociais como arenas de batalha conformadas por hierarquias internas cujo habitus, constituído individual e coletivamente, orienta as açóes dos sujeitos dentro do campo, funcionando como esquema gerador de práticas e representaçóes. Nesses espaços interativos, muito mais que um prédio e suas condiçôes materiais e recursos de financiamento, manifestam-se muitas vontades, interesses e intençôes. É nessa coletividade dinâmica que os objetivos são delineados intencionalmente, orientando a prática pedagógica, a busca (ou não) pela qualidade no ensino, bem com a formação de sujeitos participativos, conscientes e críticos na sociedade em que vivemos.

Entretanto, fundamentados nas teorizaçóes de Pierre Bourdieu, consideramos apropriado fazer algumas ressalvas, dado que tal autor foi considerado, no Brasil, como 'crítico-reprodutivista'. Nogueira e Nogueira (2014) auxiliam nessa compreensão quando pontuam que as obras desse sociólogo sobre o sistema de ensino francês foram desenvolvidas por volta de 1960 e se tornaram um marco na história do pensamento e da prática educacional em todo mundo. $\mathrm{O}$ que ocorria na França nesse período era uma profunda crise da concepção de escola existente nos anos anteriores. Até essa data, supunha-se que por intermédio da escolarização pública e gratuita seriam resolvidos os problemas de atraso econômico, autoritarismos, privilégios e oportunidades de todos os cidadãos: "A escola seria, nessa perspectiva, uma instituição neutra, que difundiria um conhecimento racional e objetivo." (NOGUEIRA; NOGUEIRA, 2014, p. 12) No entanto, em suas pesquisas Bourdieu (2011b) concluía que era principalmente o sistema de ensino que, sob a aparência de neutralidade, acabava contribuindo para a reprodução das relações de classe, justamente porque mantinha e disseminava um sistema de disposiçóes de arbitrários culturais dominantes. A igualdade de oportunidades e a justiça social passavam a ser percebidas pela reproduçáo e legitimaçáo das desigualdades sociais.

Fávaro (2014) esclarece que essa classificação 'crítico-reprodutivista' foi desenvolvida por Demerval Saviani ao criticar as teorias que denun- 
ciavam o caráter reprodutivo das instituiçóes de ensino, pois no final dos anos 70, quando a obra educacional de Bourdieu começou a circular no Brasil de forma esporádica (referências rápidas sobre o autor), não correspondia às possibilidades e expectativas de democratização do país, gerando pessimismo e insegurança nos educadores. No entanto, em Bourdieu (2011b); Bourdieu (2013); Bourdieu e Passeron (2014) a teoria do sistema de ensino enquanto violência simbólica e reprodução apontam para a necessidade de conhecer e desnaturalizar o que faz com que as estruturas sejam reproduzidas.

Em $A$ reprodução, Bourdieu e Passeron (2014) esclarecem que as condições sociais e a relação de força entre as classes de cada formação social definem os arbitrários culturais dominantes. Estes, quando são reconhecidos como legítimos e transmitidos pela ação pedagógica, acabam por exercer a reprodução social pela reproduçáo cultural. Para os autores, "[...] toda ação pedagógica (AP) é objetivamente uma violência simbólica enquanto imposição, por um poder arbitrário, de um arbitrário cultural." (op.cit., 2014, p. 26) Essa questão fica clara quando Bourdieu (1996, p. 36-37) explica que,

Para termos uma visão global do funcionamento dos mecanismos de reprodução escolar, podemos, em um primeiro momento, evocar a imagem utilizada pelo físico Maxwell para explicar como a eficácia da segunda lei da termodinâmica poderia ser anulada: Maxwell imagina um demônio que faz a triagem das partículas em movimento, mais ou menos quentes, isto é, mais ou menos rápidas, que chegam até ele, enviando as mais rápidas para um recipiente cuja temperatura se eleva e as mais lentas para outro, cuja temperatura baixa. Assim fazendo, ele mantém a diferença, a ordem que, de outro modo, tenderia a desaparecer. O sistema escolar age como o demônio de Maxwell: à custa do gasto de energia necessária para realizar a operação de triagem, ele mantém a ordem pré-existente, isto é, a separação dos alunos dotados de quantidades desiguais de capital cultural. Mais precisamente, através de uma série de operaçóes de seleção, ele separa os detentores de capital cultural herdados daqueles que não o possuem. Sendo as diferenças de aptidóes 
inseparáveis das diferenças sociais conforme o capital herdado, ele tende a manter as diferenças sociais pré-existentes.

A educação e a escola, para o sociólogo, provocam a transformação e a democratização da sociedade. Contudo, há uma forte relação entre o desempenho escolar e a origem social dos alunos (classe, etnia, sexo, local de moradia etc.), a estrutura e a organização do sistema de ensino, e seus agentes, mesmo que sem consciência disso, podem vir a contribuir, pela reprodução cultural, à reprodução social. Portanto, há limites nas instituiçóes sociais de ensino para a equalização social. Essa concepção fica evidente na apresentação do livro $A$ reprodução, na qual o autor esclarece:

Para mim, ainda hoje é surpreendente, como foi naquela época, que o fato de dizer que uma instância como o sistema de ensino contribui para conservar as estruturas sociais, ou dizer que as estruturas tendem a se conservar ou se manter - o que é uma constatação -, é surpreendente que essa constatação seja percebida como uma declaraçáo conservadora. Basta pensarmos um pouco para percebermos que o mesmo enunciado sobre a existência de mecanismos de conservação pode ter um caráter revolucionário. [...] Quando você diz as coisas são assim, pensam que você está dizendo as coisas devem ser assim, ou é bom que as coisas sejam dessa forma, ou ainda o contrário, as coisas não devem mais ser assim [...] Será que mudei? Não. Continuo a pensar que o sistema de ensino contribui para conservar. Insisto sobre o contribui, o que é muito importante aqui. Não digo conserva, reproduz; digo contribui para conservar. (BOURDIEU, 2014, p. 13-14)

Assim, diante do que foi exposto, concordamos com Fávaro (2014, p. 164) ao concluir que o objetivo de Pierre Bourdieu "[...] não foi imputar uma característica imutável nas instituiçóes, mas sim apontar seus limites diante das questóes impostas por seu tempo.”

Nessa direção é que podemos nos apropriar de seus escritos, fundamentando as questóes da dinâmica da vida social e do fazer escola, sem a intenção de mecanizar a análise. 


\section{Consideraçóes finais}

Este estudo foi sistematizado com o objetivo de refletir sobre a articulação entre os fundamentos da abordagem do Ciclo de Políticas proposta por Stephen Ball e Richard Bowe e as contribuições conceituais de Pierre Bourdieu na análise dos processos de formulação e implementação de políticas educacionais.

Conclui-se que tanto o Ciclo de Políticas quanto os conceitos de habitus, campo e poder simbólico propostos por Bourdieu implicam pesquisas que busquem inter-relaçôes e articulaçôes entre as noçôes e proposiçôes teóricas e os elementos empíricos.

A abordagem do Ciclo de Políticas aponta para uma forma de estudar as políticas públicas em seus processos e desdobramentos macro e micro políticos. Os diferentes e articulados contextos - de influência, de produção de texto e de prática - impulsionam o pesquisador a considerar a trajetória completa, complexa e controversa de uma política mediada por diferentes sujeitos, desde sua elaboração até sua implementação.

Por esse viés, os escritos de Pierre Bourdieu podem contribuir para o desvelamento das açóes, discursos, necessidades (legais e institucionais), crenças e valores discordantes, inconsistentes e contraditórios, relaçôes de poder desiguais (de vários tipos), ausências e constrangimentos materiais e contextuais dos atores que estão envolvidos com as políticas nos níveis global e local.

Portanto, nas proposiçóes teóricas de Ball e Bowe e de Bourdieu entende-se que, nos diferentes campos, classes e posiçóes na estrutura social, há relações dinâmicas marcadas por lutas de força, de sentido e de reconhecimento. Por isso, torna-se necessário que as pesquisas privilegiem as relações antes que os elementos diretamente visíveis, pois os grupos que se distribuem no espaço social são produtos de lutas históricas nas quais os agentes se comprometem em função da sua posição no espaço social e das estruturas mentais pelas quais eles apreendem esse espaço.

Assim, fica clara a importância de que sejam observados, nos campos de pesquisa, os mecanismos de manutenção e reprodução das práticas, para fins de questioná-las. Nesse movimento, busca-se a superaçáo da dicotomia objetivismo-subjetivismo, particularmente por meio do conceito de habitus, que é ao mesmo tempo individual e coletivo, e se contribui, 
significativamente, para a reprodução da ordem social, o que ocorre por adesão, reconhecimento e ação dos agentes ou grupos. O habitus está relacionado às práticas, que se constitui na relação dialética entre a estrutura e a conjuntura em que as práticas se inserem.

Em relação ao conceito de campo, em muitas obras de Bourdieu ele aparece como sinônimo de espaço social (sistema de posições sociais), que se configura de forma singular, de acordo com seus valores internos, dinâmicas, regras, conflitos, polos dominantes e outros dominados. E só pode funcionar na medida em que haja agentes para conservar ou transformar as estruturas (a conformação consensual é, em geral, inconsciente por parte dos agentes). Em cada campo há uma forma dominante de capital, seja social, cultural ou econômico. A esses tipos de capital acrescenta-se o valor simbólico, que é uma espécie de poder atribuído àqueles que obtiveram reconhecimento suficiente para ter condiçôes de impor o reconhecimento. O poder simbólico confere legitimidade ao agente ou grupo que o possui, a partir do seu reconhecimento dentro de determinado campo.

Por fim, compreendemos que a articulação dos referenciais teórico-metodológicos dos autores elencados nessa reflexáo é uma proposta valiosa para a compreensão da realidade social, para a produção de conhecimento crítico, bem como para a ação voltada ao estabelecimento de mudanças sociais

\section{Referências}

ASPRELLA, G. La Interpelación de lo cotidiano a las políticas educativas (políticas educativas, reformas y vida escolar cotidiana). In: TELLO, C. (Coord. y Comp.). Epistemologías de la politica educativa: posicionamentos, perspectivas y enfoques. Campinas, SP: Mercado das Letras, 2013.

AZEVEDO, J. L. de. Educação como política pública. São Paulo: Autores Associados, 1997.

BOURDIEU, P. Razóes práticas sobre uma teoria da ação. São Paulo: Papirus, 1996. . Esboço de uma teoria da prática. In: ORTIZ, R. (Org.). A Sociologia de Pierre Bourdieu. São Paulo: Olho d'água, 2003.

Paulo: Ed. UNESP, 2004.

Os usos sociais da ciência: por uma sociologia clínica do campo científico. São Razóes práticas. São Paulo: Papirus, 2011a. 
. O poder simbólico. Rio de Janeiro: Bertrand Brasil, 2011b.

. A Economia das trocas simbólicas. São Paulo: Perspectiva, 2011c.

. Sobre o Estado: cursos no Collège de France (1989-92). São Paulo: Companhia das Letras, 2014.

; PASSERON, Jean-Claude. A Reprodução: elementos para uma teoria do sistema de ensino. 7 ed. Petrópolis, RJ: Vozes, 2014.

FÁVARO, N. de A. L. G. O projeto político-estratégico da pedagogia histórico-crítica: uma análise das origens, do desenvolvimento, dos dilemas e da relação entre a escola pública e a luta socialista. (Tese de Doutorado). Universidade Federal de Santa Catarina, Florianópolis, 2014.

GOMES, A. M. (Org.). Políticas públicas e gestão da educação. Campinas, SP: Mercado das Letras, 2011.

HÖFLING, E. de M. Estado e políticas (públicas) sociais. Cadernos de Educação. CEDES, v. 21, n. 55, 30-41, 2001.

MAINARDES, J. Abordagem do ciclo de políticas: uma contribuição para a análise de políticas educacionais. Educação e Sociedade, v. 27, n. 94, 47-69, 2006.

; GANDIN, L. A. A Abordagem do ciclo de políticas como epistemetodologia: usos no Brasil e contribuições para a pesquisa sobre políticas educacionais. In: TELLO, C., ALMEIDA, M. L. P. (orgs.) Estudos epistemológicos no campo da pesquisa em politica educacional. Campinas,SP: Mercado de Letras, 2013, p. 143-167.

; FERREIRA, M. dos S., TELLO, C. Análise de políticas: fundamentos e 